Обсудить с кем-то то, что человек боится услышать и попробовать выявить источник первоначальной проблемы.

Полюбить себя, как бы банально это не звучало.

Поставить собственное мнение выше мнения других и стараться не зацикливаться на общественном мнении.

Работать над уверенностью в себе.

6. Комплекс отличника/отличницы - это обесценивание собственных достижений, желание делать все идеально и быть всегда впереди

Если ты волнуешься из-за чего-то и понимаешь, что спустя пару лет это тебя не будет волновать, то не стоит обращать на это внимание сейчас.

Понять, что человек - не машина, которая делает всё идеально и без ошибок.

Прикладывать максимальные усилия, ведь только в этом случае будешь понимать, что ты сделал(а) всё, зависящее от тебя.

В некоторых ситуациях стоит проявить безразличие.

Вывод:

На основе вышесказанного можно сделать вывод: бороться с комплексами нужно, потому что большинство из них негативно влияют на психику подростка и на его дальнейшую жизнь в целом, мешают реализации себя в том или ином деле. Для решения этой проблемы стоит провести самоанализ и выявить, какие методы устранения комплексов неполноценности являются наиболее подходящими для вас. Не стоит думать, как решить эту проблему: повысить самооценку, улучшить свою внешность, приобрести уверенность в себе - нужно начать действовать прямо сейчас. Подумать, какие навыки у вас уже и какие вы хотите получить, чтобы победить свои комплексы.

$$
* * *
$$

1. Комплекс неполноценности и комплекс превосходства/ Адлер А. - 1997.

2. Комплекс собственной неполноценности / Тесленко И.И.// Медицина третьего тисячолетия: сборник тезисов межвузовской конференции молодых ученых и студентов. - 2016.

3. Комплексы в подростковом возрасте/ Запашный А.М. - 1985.

4. Психология: Учебник для бакалавров/ Ступницкий В.П., Щербакова О.И., Степанов В.Е. — 2013.

5. Акимова М.К. Психология. Учебное пособие. - Москва: «Педагогика», 2003. - 489c.

6. Асмолов А.С. Психология личности. М.: ЮНИТИ-ДАНА, 2003.

7. Запашный А.М. Комплексы в подрастковом возрасте. Монография. Новосибирск, 1985.

8. Кедров Б.М. Психология. Учебное пособие. - Москва: «Наука», 2001. - 113с.

9. Козлов В.И. Формула личности. СПб: Питер, 2000.

10. Козлова В.Т. Психология и культура. Учебное пособие. - Москва: «Наука», 2001. - 612c.

\title{
Лифенко И.И. \\ Особенности формирования половозрастной идентификации у детей дошкольного возраста
}

ФГБОУ ВО «ХГУ им. Н.Ф. Катанова»

(Россия, Абакан)

doi: $10.18411 / \mathrm{lj}-06-2021-300$

\section{Аннотация}

Проблемой сходства и различий в психологии мужчин и женщин занимаются уже несколько поколений ученых. Воспитание детей без учёта особенностей биологического пола способствовало и способствует тому, что немало молодых людей в силу отсутствия у них основополагающих представлений о «мужественности» и «женственности» и при отсутствии полового воспитания в совокупности с конфликтными ситуациями в процессе принятия своей гендерной роли погружаются во внутриличностные конфликтны и живут в разрез с установленными нормами общества. 
Изучение процессов формирования гендерной идентичности поможет направить половое воспитание в нужное русло. От этого многое зависит в формировании будущей личности, а именно: уверенность в себе, наличие устойчивых личностных установок, и в итоге эффективность общения с людьми, благополучие семейных отношений.

Ключевые слова: пол, гендер, гендерная идентификация, половозрастная идентификация, процесс формирования.

\section{Abstract}

Several generations of scientists have been dealing with the problem of similarities and differences in the psychology of men and women. The upbringing of children without taking into account the characteristics of the biological sex has contributed and contributes to the fact that many young people, due to their lack of fundamental ideas about "masculinity" and "femininity" and in the absence of sex education in conjunction with conflict situations in the process of assuming their gender role, are immersed in intrapersonal they are conflicted and live at odds with the established norms of society. Studying the processes of forming gender identity will help to direct sex education in the right direction. Much depends on this in the formation of the future personality, namely: self-confidence, the presence of stable personal attitudes, and, as a result, the effectiveness of communication with people, the wellbeing of family relations.

Keywords: sex, gender, gender identity, gender and age identification, formation process.

По результатам диагностики по методике Н. Л. Белопольской «Половозрастная идентификация» можно сделать вывод о влиянии социальной ситуации развития ребенка, его опыта на предпочтения ребенка при построении половозрастной последовательности и при выборе привлекательного и непривлекательного образов последовательности в разные возрастные периоды.

Мальчики 3-4-х летнего возраста относят себя к мужскому полу, только вот считают себя в большинстве случаев старше, чем есть на самом деле (выбор мужского пола, но не соответствующего возрасту ребенка). Они предпочитают видеть себя школьниками, юношами и даже мужчинами или совсем младенцами (см. рис. 1).

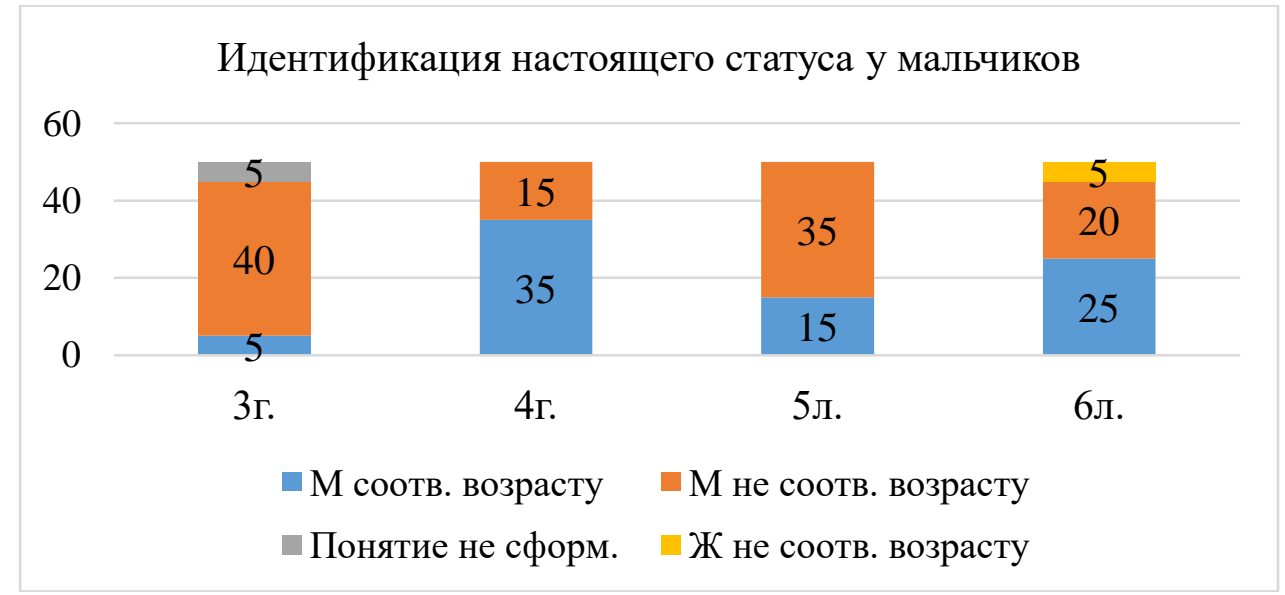

Рис. 1. Идентификации своего настоящего статуса у мальчиков

Из рисунка 2 видно, что одна из девочек в 3 года идентифицирует себя с мужским полом (младенец-мальчик), объясняя: «Это я подросла». Скорее всего, у неё ещё не сформировано понятие принадлежности к своему полу. Во всех остальных возрастах девочки точно идентифицируют себя с женским полом, только варьирует количество их в соответствии или в несоответствии с возрастом. 
В таблице 1 представлены статистически значимые различия по каждой возрастной группе и по каждому параметру исследования. Значимые различия в идентификации своего пола имеются между возрастом детей в 3-4 года и 4-5 лет $\left(\varphi^{*}=2,27, \mathrm{p} \leq 0,01\right)$. Девочки точно идентифицируют себя с женским полом, только варьирует количество их в соответствии или в несоответствии с возрастом.

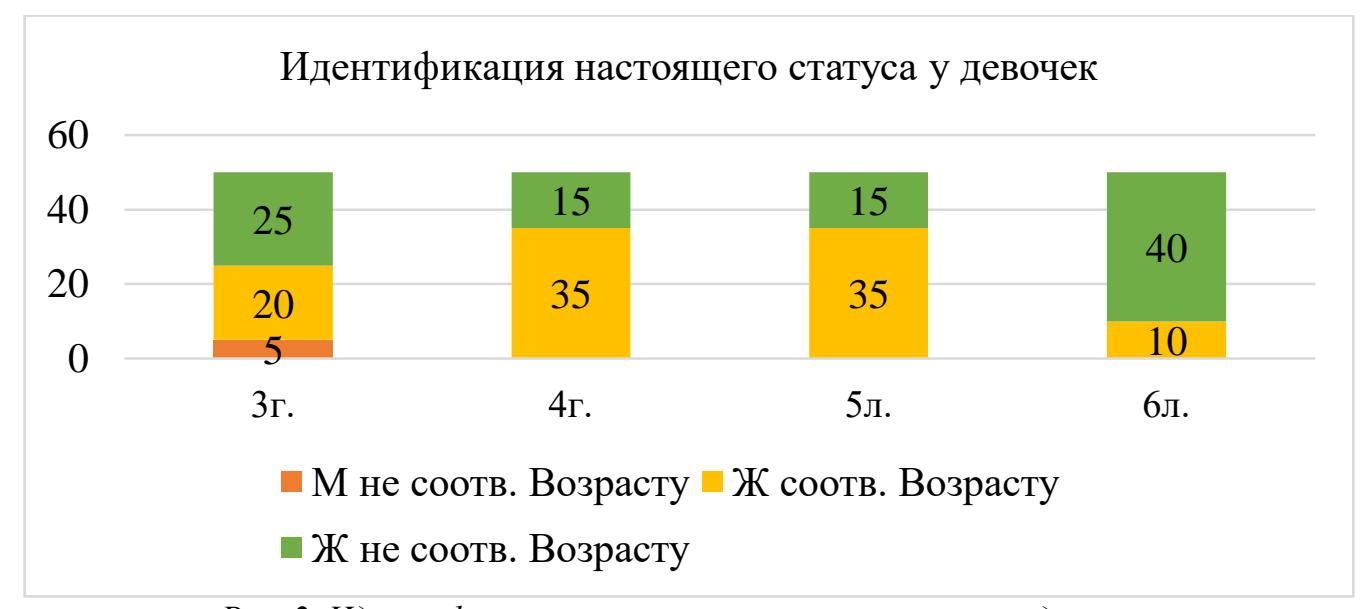

Рис. 2. Идентификация своего настоящего статуса у девочек.

Так, например, в возрасте 6 лет резко увеличивается количество выборов идентификации своего настоящего статуса несоответствующего возрасту $\left(\varphi^{*}=1,62\right.$, $\mathrm{p} \leq 0,05)$. Чаще всего девочки хотят быть старше - школьницами или девушками, они раньше, чем мальчики готовы к будущим ролям.

Однако уже в 4 года ситуация резко меняется, о чём свидетельствуют значимые различия между двумя этими возрастами $\left(\varphi^{*}=2,27, \mathrm{p} \leq 0,01\right)$. После 4-летнего возраста мальчики выстраивают последовательность идентификации от младенца до старика, пропуская часто образы юношей или мужчин, и редко делая смешанный выбор. В 6 лет мальчики уже точно идентифицируют свой жизненный путь по сравнению с 5-летними детьми, то есть, они имеют представления о прошлых и будущих возрастных ролях родителей, бабушек и дедушек $\left(\varphi^{*}=1,62, \mathrm{p} \leq 0,05\right)$.

Девочки в 3 года также неадекватно идентифицируют свой жизненный путь, показывая существенную разницу с 4-х-летним возрастом $\left(\varphi^{*}=1,62, p \leq 0,05\right)$ и чаще выбирая смешанную последовательность, то есть они могут быть и мальчиками, и дядями. После 4-летнего возраста девочки уже не делают смешанный выбор в половозрастной последовательности (См. рис. 4).

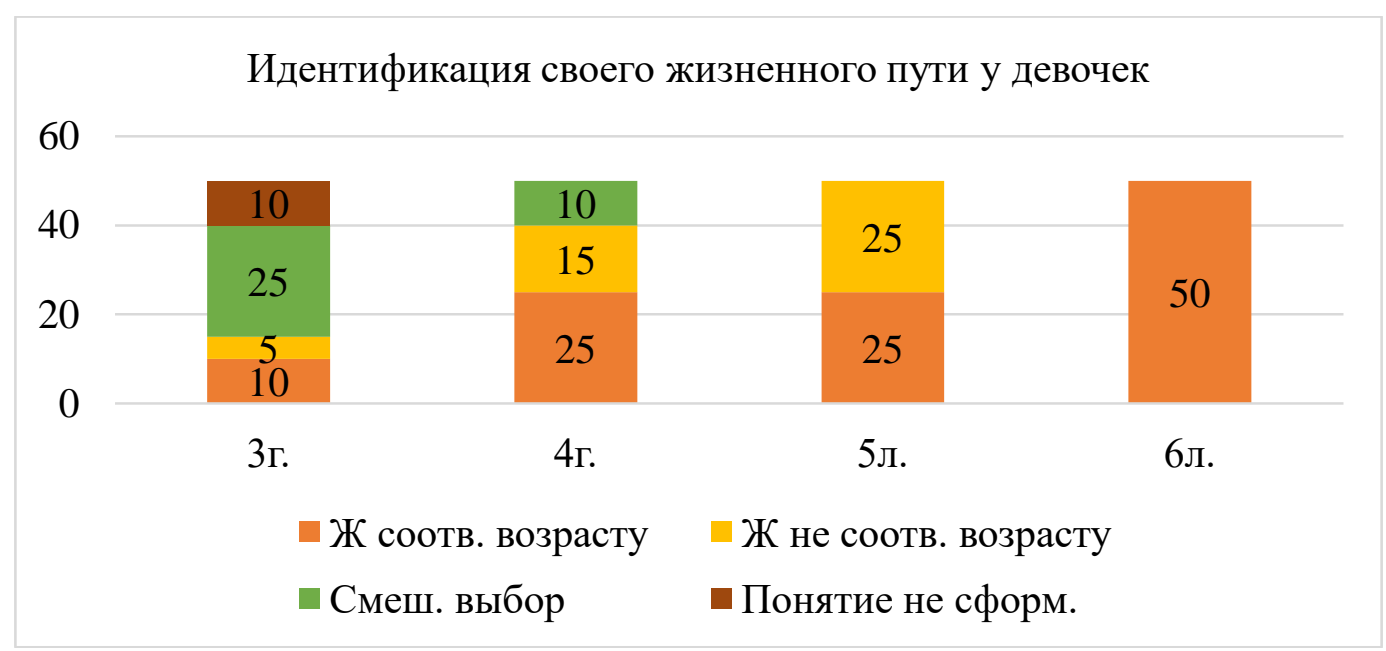

Рис. 4. Идентификация своего жизненного пути у девочек 
В 6-летнем возрасте девочки четко представляют свои будущие роли по сравнению с предыдущими возрастами $\left(\varphi^{*}=3,51, p \leq 0,01\right)$.

Таким образом, у детей уже в дошкольном детстве складываются определённые представления о смене физического облика человека, его половых и социальных ролей в связи с возрастом. Это знание основывается на присвоении общественного опыта и развитии самосознания. Дети 6-7-летнего возраста спокойно идентифицируют себя с образом старости, хотя в большинстве случаев считают его самым непривлекательным.

Мальчики, начиная с 3-х летнего возраста, наиболее привлекательными считают лиц мужского пола, а к 6 годам так и вовсе только мужской пол. До 4-х летнего возраста привлекательными больше являются младенцы, а в 5 лет привлекательными становятся юноши и мальчики своего возраста. Представительницы женского пола теряют для мальчиков свою привлекательность, различия между выбором мужского и женского пола как привлекательного здесь становятся значимыми $\left(\varphi^{*}=2,27, \mathrm{p} \leq 0,01\right)$. В 6 лет привлекательными становятся школьники, юноши и мужчины (женского пола как привлекательного нет вообще).

У девочек во всех возрастах присутствует выбор мужского пола как привлекательного, причем предпочтение отдается выбору младенца - мальчика, особенно в возрасте 5 и 6 лет, объясняя при этом: «Я люблю маленьких; люблю нянчиться; он красивый». В 6 лет самым привлекательным оказался образ девушки, так как она или добрая как мама, или красивая, с цветочком. Достоверные различия в выборе привлекательного пола появляются после 5 лет $\left(\varphi^{*}=1,62, p \leq 0,05\right)$ и они принадлежат женскому полу.

Интересным является тот факт, что и мальчики, и девочки самым непривлекательным образом считают лиц мужского пола (См. рис. 7).

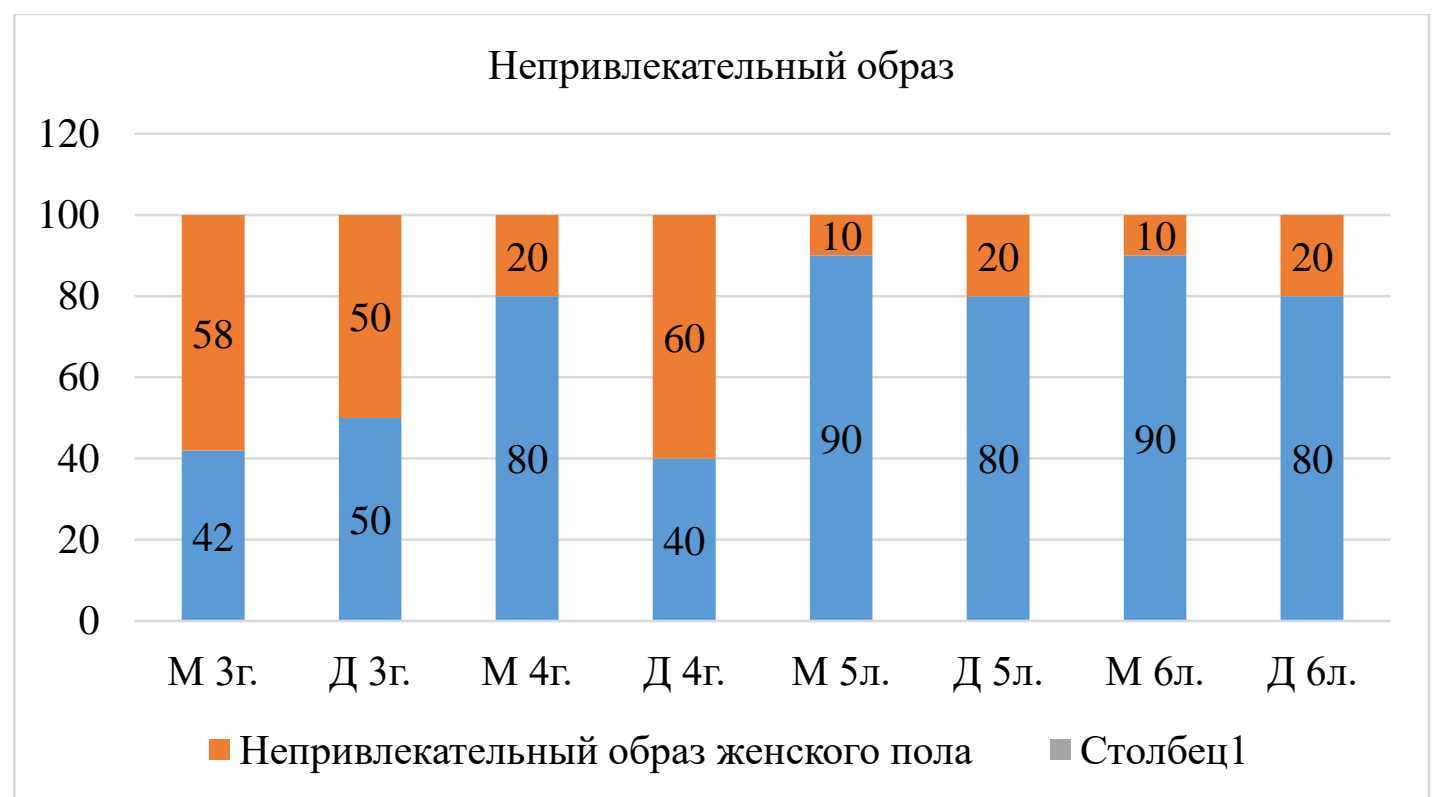

Рис. 7. Выбор непривлекательного образа мужского и женского пола мальчиками и девочками

Мальчики в 3 года непривлекательными могут считать лиц обоего пола (нет особых различий), а уже в 4 года превалирует выбор своего пола как непривлекательного $\left(\varphi^{*}=1,62, p \leq 0,05\right)$. В 5 лет различия увеличиваются $\left(\varphi^{*}=2,27\right.$, $\mathrm{p} \leq 0,01)$, мальчикам больше не нравится образ мужчины, по их мнению, он либо не сильный, либо бандит, а в 6 лет больше не нравятся младенцы и старики и различия остаются достоверными ( $\left.\varphi^{*}=2,27, \mathrm{p} \leq 0,01\right)$. Девочки более непривлекательными лиц мужского пола начинают считать с 5 лет и продолжают так считать и в возрасте 6-7лет, 
демонстрируя нам одинаковые различия в этих возрастах $\left(\varphi^{*}=1,62, p \leq 0,05\right)$. В 5 лет это могут быть мальчики - школьники и старики, а в 6 лет мужчины и старики.

Таблииа 1.

Статистические данные половозрастной идентификации дошкольников

\begin{tabular}{|c|c|c|c|c|c|c|c|c|}
\hline \multirow[t]{2}{*}{ 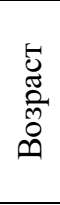 } & \multicolumn{2}{|c|}{$\begin{array}{c}\text { Различия в } \\
\text { идентификации } \\
\text { своего настоящего } \\
\text { статуса. } \\
\end{array}$} & \multicolumn{2}{|c|}{$\begin{array}{c}\text { Различия в } \\
\text { идентификации } \\
\text { своего жизненного } \\
\text { пути } \\
\end{array}$} & \multicolumn{2}{|c|}{$\begin{array}{c}\text { Различия в выборе } \\
\text { привлекательного } \\
\text { образа }\end{array}$} & \multicolumn{2}{|c|}{$\begin{array}{c}\text { Различия в выборе } \\
\text { непривлекательного } \\
\text { образа }\end{array}$} \\
\hline & $\mathrm{M}$ & Д & $\mathrm{M}$ & Д & $\mathrm{M}$ & Д & $\mathrm{M}$ & Д \\
\hline $3-4$ & $2,27 * *$ & 0,51 & $2,27 * *$ & $1,62 *$ & 1,39 & 1,05 & 0,29 & 0 \\
\hline $4-5$ & 1,05 & 1,05 & 0,51 & 0 & 1,05 & 0,51 & $1,62 *$ & 0,51 \\
\hline $5-6$ & 1,05 & 1,05 & 0,51 & 0 & $2,27 * *$ & $1,62 *$ & $2,27 * *$ & $1,62 *$ \\
\hline $6-7$ & 0 & $1,62 *$ & $1,62 *$ & $3,51 * *$ & $3,51 * *$ & $1,62 *$ & 2,27 ** & $1,62 *$ \\
\hline
\end{tabular}

$p^{*} \leq 0,05 ; p^{* * \leq 0,01}$

Как видно из таблицы 1 статистически значимые различия обнаружены в идентификации своего настоящего статуса (принадлежность к своему полу) у мальчиков между 3-4 годами и остальными возрастами, то есть в 3-4 года мальчики ещё не идентифицируют свой настоящий статус. Девочки же в 6-7 лет значительно отличаются по этому параметру от других возрастов тем, что они чётко идентифицируют свой настоящий статус. Различия в идентификации своего жизненного пути сначала наблюдаются у детей от 3 до 4 лет, как у мальчиков, так и у девочек. И в основном эти различия из-за того, что у детей только начинают формироваться такие понятия, а в возрасте 6-7 лет, когда они уже сформированы, дети вновь демонстрируют нам достоверные различия по всем исследуемым параметрам.

\section{Медникова Е.C.}

Взаимосвязь психологического и физиологического стресса: теоретический обзор исследований

Волгоградский государственный медиџинский университет (Россия, Волгоград)

doi: $10.18411 / 1 j-06-2021-301$

Научный руководитель

Озерина А.A.

\section{Аннотация}

В данной статье рассматриваются понятие стресса, его виды, взаимосвязь психологической и физиологической сторон стресса, «классические» стрессогенные воздействия различного характера, и стрессоры современного мира. Анализ современных исследований и изучение процесса стресс-реакции на неблагоприятные воздействия и последствия переживаемого стресса. Рассмотрены аспекты, обуславливающие появление психического и соматовегетативного расстройства у индивида вследствие длительного неблагоприятного воздействия.

Ключевые слова: стресс, стрессор, взаимосвязь, психологический стресс, физиологический стресс.

\section{Abstract}

This article examines the concept of stress, its types, the relationship between the psychological and physiological aspects of stress, "classical" stressful influences of a different nature, and stressors of the modern world. Analysis of modern research and study of the process of stress-reaction to adverse effects and consequences of the stress experienced. The 